\title{
Cartographic visualization of density: exploring the opportunities and constraints of Heat Maps
}

\begin{abstract}
The authors of the review aim to understand and assess cartographic Heat Maps' (HM) designs, tools, and applications. The paper consists of two parts. First describes HM in the context of neocartography and map design by tackling such issues as definition, input data, methods of density determination and generalization, colour schemes, legend construction, and base maps. The second part assesses the range of 17 tools used for creating HM. Tools are divided into non-GIS tools (visualization tools and programming libraries) and GIS applications (desktop and webGIS). GIS desktop software has been selected due to its popularity and wide application. Paper presents an expert assessment of this software with the use of a research questionnaire. The analysis made it possible to develop a division of tools based on their embedding in computer programs and applications and taking into account the types of visualization. It also made it possible to indicate tools that can be used by both professional GIS users (e.g. analysts, cartographers) and the general public, including teachers using HM to visualize geo data for geography lessons. The limitation of the review was the analysis from the expert's point of view. It would be desirable to include novices perspectives in future studies due to the wide demand for visualization.
\end{abstract}

Keywords: Heat Map, GIS, visualization, thematic mapping, generalization, ArcGIS, QGIS

\section{Introduction}

The development of Geographic Information Systems (GIS) software and its growing popularity among users outside the spatial information environment has contributed to the interest in new forms of data visualization that go beyond traditional types used in cartography and applied graphics. GIS is used in various web applications that enable the collection, analysis and visualization of spatial data. The current development of cartography in the context of Web 2.0, which emphasizes user-generated content, ease of use, and participatory culture, has resulted in the term "neocartography" (Faby \& Koch, 2010). Online applications are widely used in neocartography. This often means that people who do not have proper knowledge of mapmaking do make maps. Therefore, it is crucial to provide manuals, tutorials and instructions for them. Besides, not all tools and applications allow mapmaking according to the mapping princi- ples adopted in cartography, and some even make it harder. This phenomenon is quite common, which is why a separate Commission on Neocartography was set up in 2011 as part of the International Cartographic Association (Kukułka \& Gotlib, 2014). Because of the development of social cartography and neocartography, cartographers should develop procedures for spatial data processing, assessing maps available on the Web as well as identifying the solutions for proper mapmaking (Gotlib, 2008).

One type of cartographic visualization that is particularly relevant for neocartography are Heat Maps (hereinafter referred to as HM), i.e. the presentations of 'geospatial data on the map using different colours to represent areas with different concentrations of points - showing the overall shape and trends of concentration' (Yeap \& Uy, 2014). It is a type of visualization used to graphically represent the density of phenomena (Pettit et al., 2012; Wilkinson \& Friendly, 2009). De Boer points out that the term itself is 
not conclusive and can mean both a density map (regardless of the method used) and the process of interpolating (estimating) point data to surface data (DeBoer, 2015). Dempsey (2012) noted that $\mathrm{HM}$, which are subjective maps, must be distinguished from an objective hotspot map based on geostatistical analysis with a certain level of statistical significance of data. According to Dempsey, HM subjectivity (which is difficult to disagree with) stems from the arbitrariness of the selection of parameters resulting in different generalizations or colours on the resulting map.

This map type is used in many fields of science, besides geography and cartography. For example, it is used in medicine to visualize the distribution of steroid metabolism in the human body (Moon et al., 2009), in chemistry to analyze the density of decomposition of molecules (Rosenbaum et al., 2011), and in biology and ecology to visualize environmental and biological indexes (Pleil et al., 2011). In the social sciences, HM present the links and density of social networks (Gove et al., n.d.). Such visualization is used in analysis and visualizations related to the statistics of movement of teams or individual players on the football field (Bornn et al., 2018; McHale \& Relton, 2018; Perin et al., 2013) and in basketball (Goldsberry, 2012). It is also one of the ways of visualizing eye movement studies using an eye-tracker (Guo et al., 2020; Scott et al., 2016; Špakov \& Miniotas, 2007; Zhan et al., 2016), which is used, for example, for web design, advertising, but also empirical analysis of map usability (Opach \& Nossum, 2011). HM as a map type were taken from widely understood utility graphics, as well as some other sources (e.g. diagrams or charts). Presenting data using the HM method may evoke positive or negative emotions in the map recipient, not always in line with the map's author's intention.

The application of HM in cartography can be viewed from two perspectives: data (cartographic visualization of spatial phenomena) and design (different approaches for HM elaboration, such as generalization, base map or colour scales). In previous works, much more space has been devoted to specific spatial analysis (for which HM were only a way of visualizing phenomena) than to its methodological aspects. Analysis of the literature shows that, in the geographical context, HM have been used in, for example, studies of spatial diversity of social problems (Borzuchowska, 2007; Silva et al., 2016), visualization of the routes of runners and cyclists (Nelson \& MacEachren, n.d.; Pánek \& Benediktsson, 2017; Sainio et al., 2015), criminal analysis (Chainey et al., 2008) and road accident analysis (Anderson, 2009; Plug et al., 2011). In these studies, HM were used to develop a quantitative (synthesizing) map relatively quickly based on qualitative data that at the nominal level only described the distribution of the phenomenon. The transition from a qualitative to quantitative approach is made by switching from source data (mostly point, less linear) to interpolated (surface) data. The reference surface of HM are not statistical units, but regular fields (raster map) with a specified spatial resolution and generalization. Hence the speed of execution of such maps, which determines their popularity.

The article is intended for a wide audience, people, who professionally and scientifically deal with the processing and visualization of spatial data can familiarize themselves with the available tools in GIS programs, their characteristics and evaluation. People, who perform visualization will occasionally find in the article information on the availability of HM visualization tools through on-line tools. The variety of $\mathrm{HM}$ applications and the postulates made by cartographers on the need to develop guidelines for the correct use of visualization tools by people not involved in mapping professionally have led the authors to study this type of visualization in the context of (1) methodological variables affecting its form and (2) tools for its development (non-geographical and geographical). The article consists of two parts: a review on $\mathrm{HM}$ as a type of cartographic presentation, and characteristics, assessment and evaluation of selected tools and applications that enable HM creation.

\section{Aims and methods}

The first part discusses HM as a type of thematic map often used in Internet cartography and neocartography in the context of methodological variables affecting its form. Based on the literature and the review of HM developed so far, six factors have been identified that determine this map type, and therefore its scope, form and reception. These include input data 
(nature and spatial reference), density determination methods (kernel density, hotspot, density), degree of generalization (HM details/ resolution), colour scales and graphics (singleand multi-toned scale; transparency), legend (presence, design) and selection of base map (topographic map; satellite imagery; no base map). These variables can be considered the most relevant in the context of the correct and effective development of $\mathrm{HM}$, which is extremely important in the era of neocartography.

The second part of the article covers the characteristics, assessment and evaluation of selected applications that enable HM creation. Tools were divided into two major groups: non-GIS and GIS software, however, the main focus of the paper was on GIS tools (web and desktop). For the webGIS tools (e.g. OpenLayers, Google Maps API or Heatmapper), we have indicted main features and characteristics and for desktop GIS (ArcGIS, QGIS, SAGA, MapInfo) the assessment was performed in the context of possibilities and constraints of $\mathrm{HM}$ creation. In the evaluation we have taken under consideration such features as: customizing HM parameters (radius, colour scheme) and type of map legend, but also technical support and difficulty of usage. The importance of the latter factors is growing in the era of neocartography which should not result in creating incorrectly made maps. A summary developed on the popular GIS LOUNGE portal was also used in this part of the study (Dempsey, 2012) and the context of big data was taken under consideration (Netek et al., 2019).

\section{The Heat Map in cartography: methodical variables}

\subsection{Input data}

HM visualize the density of phenomena and is based on point data, or, less often, linear data, usually with no statistical value. The typical input data for HM could be the location of crimes, point of interests, or any other single objects. Not all types of spatial data should be visualized using this map type even if GIS software may allow it. HM should be used to present discontinuous (discrete) data, e.g. density of buildings performing a specific function, social data or the presence of animal species, rather than continuous data such as temperature or altitude. This nature of the data thus distinguishes HM from isoline maps. Despite sometimes being similar in form, HM must also be distinguished from the choropleth map, which was highlighted by Netek et al. (2018). Choropleth maps are used to describe statistical aspects of areas, e.g. populations in municipalities or counties. Sometimes choropleth maps resemble HM in form, e.g. in terms of colour scales or data used (absolute data), but they represent different kind of information. HM show the estimated density of phenomena rather than an aggregation of data into statistical areas.

\subsection{Density determination}

The density determination method like $\mathrm{HM}$ allow converting data from a point without an additional attribute value to an area. This method differs from the IDW and Kriging interpolation methods common in GIS programs, which require different attribute values in addition to locating the point of occurrence.

In $\mathrm{HM}$, an important role is played by the change of data representation from point to surface, and in many publications, HM are linked to the issue of spatial data interpretation (Pettit et al., 2012; Pleil et al., 2011; Yeap \& Uy, 2014). In GIS software, HM are most commonly used to communicate the spatial distribution of a phenomenon based on point data using a surface data density algorithm based on kernel estimation (Kernel Density Estimation and point/line density estimation (Point/Line Density Estimation) (ESRI, 2020; Silverman, 1986).

The principle of operation of the former (kernel estimation) is as follows: a curved area is defined around each point with a scope defined by the cartographer. The value of the raster cell is the largest in the centre of this area and reaches zero at its ends. The resulting map represents the sum of the values of the defined surfaces superimposed on each screen cell. The second method (point/line density estimation) is designed to generate an area with a defined scope around each point. The value of each cell on the resulting map is the number of points that are normalized in that area by its surface.

In both algorithms, regardless of the differences between them, it is crucial to determine 
the size of the area within which the input points are counted. Such an area is defined in the GIS software using a radius, the length of which determines the scope of the search for the nearest points, thereby determining the detail and degree of generalization of the map. The right choice of radius value is crucial and determines the correct interpretation of the phenomenon represented on the map (fig. 1). The choice of radius depends on the nature of the phenomenon and the scale of the map, so universal values cannot be provided.

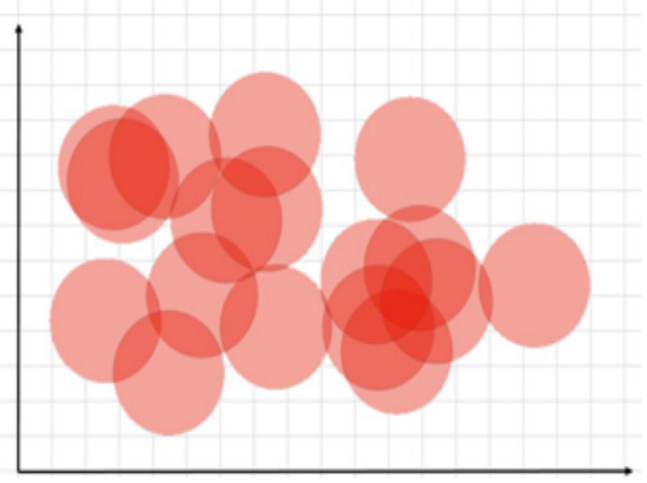

Fig. 1. The graphical method of creation of a Heat Map with overlapping buffers

\subsection{Generalization}

HM by definition present highly generalized data, and the areas with the highest density of a phenomenon are in the foreground, usually resembling highly meaningful clusters (Board, 1978). The input data is the topographically localized points at which the phenomenon was observed or measured. Depending on the radius of the kernel estimation, the data are processed into a more or less generalized image: the larger the radius, the greater the generalization. Generalization means, above all, highlighting the places with the highest density of the phenomenon by emphasizing its surface and gradually disappearing low-density areas. Due to its specificity, interpolated data do not depend on administrative or statistical boundaries, so $\mathrm{HM}$ can give more to spatial patterns than, for example, a choropleth map. It seems that, in web and interactive maps, the issue of generalization does not perform such an important function, because the user can zoom in or out (zoom on slippy map), and thus adjust the generalization to their optimal level (fig. 2).

HM which are simply printed or static (displayed without the ability to zoom in and out) constitute an significant issue. A crucial role here is the analysis of the input data and the identification of the places to be shown by the cartographer on the $\mathrm{HM}$ as the places with the
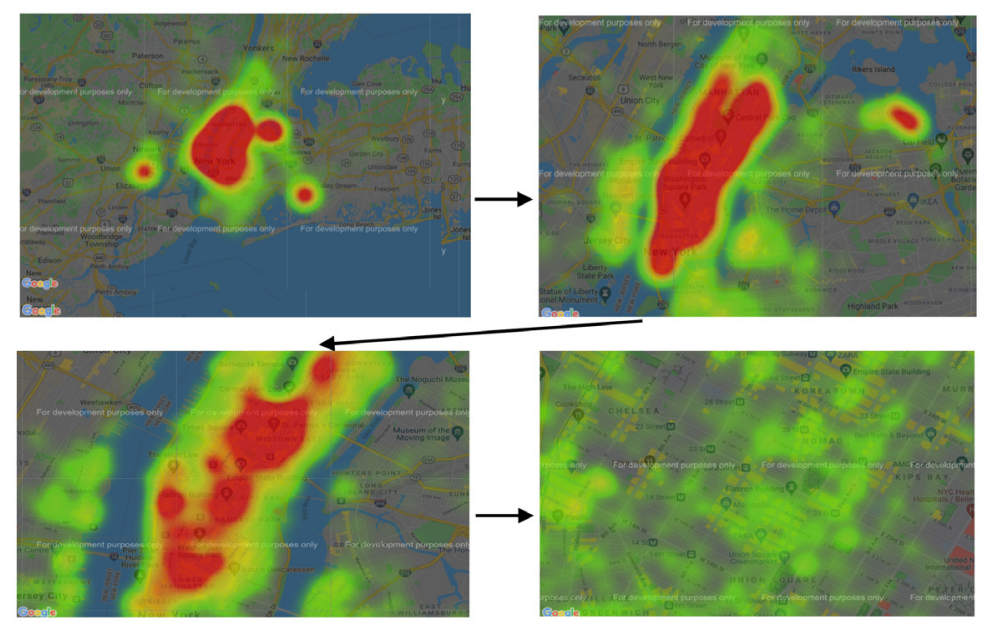

Fig. 2. Heat map of Uber travel density in New York city at different scale levels (Uber Heat Map, n.n, https:// xlinesoft.com/livedemo/uber_trip_data/Uber_Heat_Map_list.php, accessed: 15.12.2020) 
highest density of the phenomenon ('hotspots'). Unfortunately, it is not possible to indicate uniform rules regarding the degree of generalization. Most often, the person who prepares the map selects the value of the radius that best reflects the spatial patterns.

\subsection{Symbology}

The colour is the graphic variable showing the density of phenomena in HM. The most commonly used colour scales are the spectral scale (from blue to green to red, fig. 2) and hypsometric scales (green to yellow to red or brown, fig. 2). Hence the name of the map type: Heat Map.

Although multitone scales are most commonly used, there are also other types, such as those used in the online visualization of running and cycling routes of Strava users (Strava, n.d.). Users of the application have the opportunity to choose four colour scales: hot, blue, purple, gray, and red. 'Hot' colours (multitone) represent a scale from white (high intensity), through yellow to red (low intensity), which are presented on a highly generalized OpenStreetMap in black tones. HM in blue (brighter - high intensity; darker - low intensity) are presented on the same base map. The scale, quite mistakenly called grayscale, is actually from blue (high intensity), through yellow and orange (medium intensity) to red (low intensity), and is presented on the OpenStreetMap (OSM) underlay in shades of gray. The same base map was used for presentations on a red scale, where reds correspond to high intensity and blue to low. Besides, to better distinguish between more and less frequently selected routes, the application also uses a variable thickness: routes with a higher intensity of runners and cyclists are slightly thicker (fig. 3).

User preferences can, based on previous HM research, be described in two ways: users identifying themselves as 'cartographers' prefer single-tone convergent scales, and 'non-cartographers' prefer multitone divergent scales, e.g. hypsometric scale (Anderson, 2009). As recent studies by I. Gołębiowska and A. Çöltekin have shown, the rainbow scale is very popular despite being significantly less efficient than single-tone scales in correctly ordering values on the map (Gołębiowska \& Coltekin, 2020).
However, the rainbow scale allows for a fairly correct reading of specific values.

If the map element, in addition to the thematic content, is also a more graphically complex base map, then the thematic layer (HM) is given a certain degree of transparency, which provides visibility of the reference content. A user preference surveys show that the best solution is $50 \%$ transparency of thematic content and that the worst is $0 \%$, i.e. lack of transparency (Netek et al., 2018).

\subsection{Legend}

$\mathrm{HM}$ are one of the map types in which a legend is not necessary for correct interpretation. It is a so-called map for quick reading, on which the most important elements ('hotspots') stand out graphically from other elements. The colour scales should allow users to easily locate the areas with the highest density of the phenomenon. Also, such areas in the map area are usually relatively few, which is due to the nature of this map type - to show the most concentrated areas (among all). Legends that are placed in Heat Maps are usually referred to as one of two measurement levels: ordinal (high-low) or (less often) ratio (calculated density of the phenomenon in a given class represented by a certain colour).

\subsection{Basemap}

In web maps, the most commonly used base map is the basic Google Maps or OSM map (fig. 2, fig. 3). Some applications (e.g. Strava) allow users to manipulate with base maps by changing the transparency of HM (and thereby the visibility of the base map), enabling or disabling annotations, or even changing the underlying map from the street network to satellite imagery (Strava, n.d.). For paper maps, the base map can be, for example, a generalized grid of streets, hydrography, or administrative boundaries.

\section{Tools evaluation}

A query conducted within the webGIS tools and access to GIS software packages allowed for a review of the tools enabling the development of HM. First, we present an overview of 


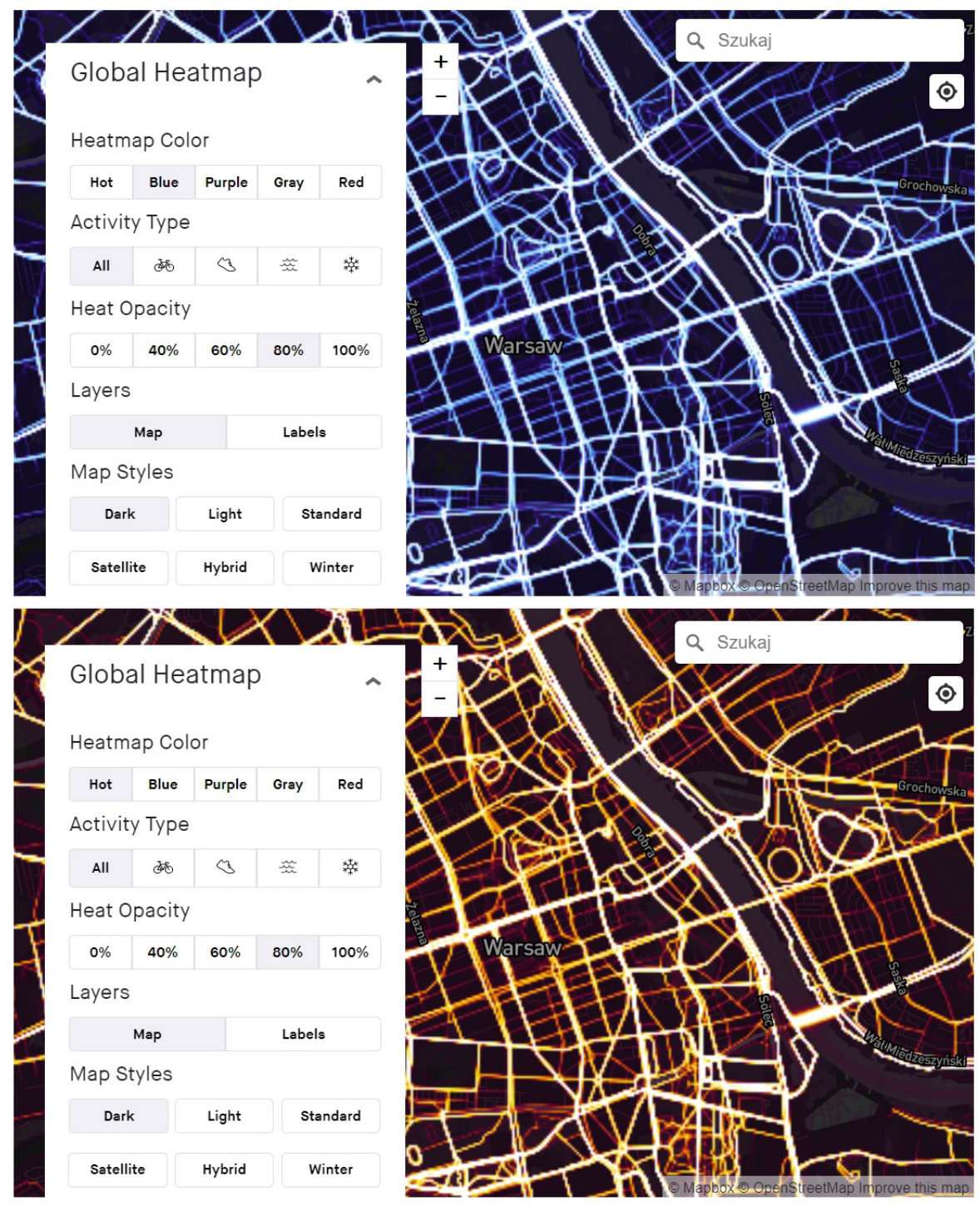

Fig. 3. Presentation of the density of routes of runners and cyclists along the streets in the Strava app in two color scales Hot and Blue (Strava, n.d., https://www.strava.com/heatmap\#13.64/21.00488/52.23799/blue/all, access: 10.06 .2021$)$

selected tools for the development of HM which are available via web browsers and that allow maps to be developed by people unfamiliar with GIS software. Subsequently, the tools for developing HM as components of GIS software were presented and evaluated. The study consisted of evaluating the functionality of the tool when developing maps based on the same data and, where possible, using identical parameters of the map being developed. A review and study on the possibility of using GIS software to develop HM allowed programs and applications to be divided into three groups (fig. 4).

The first group are tools applications and tools defined as outside GIS (non-GIS tools), 


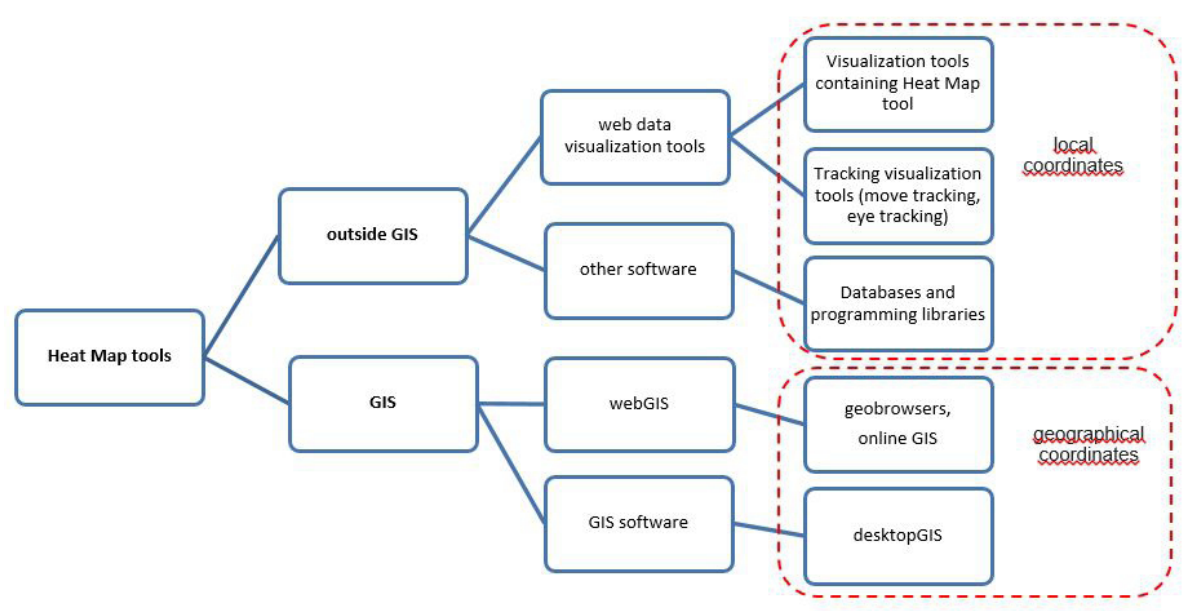

Fig. 4. Division of Heat Map tools and applications

which are not related to GIS software. This group also includes tools enabling the visualization of recorded paths during outdoor activities (chapter 4.1). Next group consists applications related to webGIS technology (chapter 4.2). Another group of tools occurs as components of GIS software (chapter 4.3). The second division of tools is between tools for visualizing spatial data in the cartographic sense (data with cartographic coordinates) and tools for other data related to locations on a computer screen or at the microscale in commercial premises (shelves with goods, exhibition stands), on sports fields or sports floors. Only certain web applications allow map development according to the principles adopted in digital cartography.

\subsection{Non-GIS tools}

Non-GIS tools are generally tools not specifically designed for visualizing spatial data of a geographic nature. In the simplest way, HM can be created in a Microsoft Excel (Microsoft Excel Heatmap, n.d.) spreadsheet using collected numerical data and a method of data visualization called Conditional formatting (fig. 5). This method allows you to colour individual cells based on their numeric values.

A more advanced form of Heat Map development in a spreadsheet uses scripts written in Visual Basic for Applications (VBA). An example of such a solution is an application - a script used to calculate a map based on data entered into a spreadsheet - that is then visualized using the Google Earth virtual globe interface. For example, such a script was used to develop a map of the defensive capabilities of the eastern Polish border in the 17th century (Polczynski \& Polczynski, 2014).

Among the tools and applications that enable HM development, one group allows the behavior of customers on a selected website to be monitored by tracking cursor movement and mouse clicks, and developing a HM base on that. For example, the Smartlook (Smartlook, n.d.) appli-

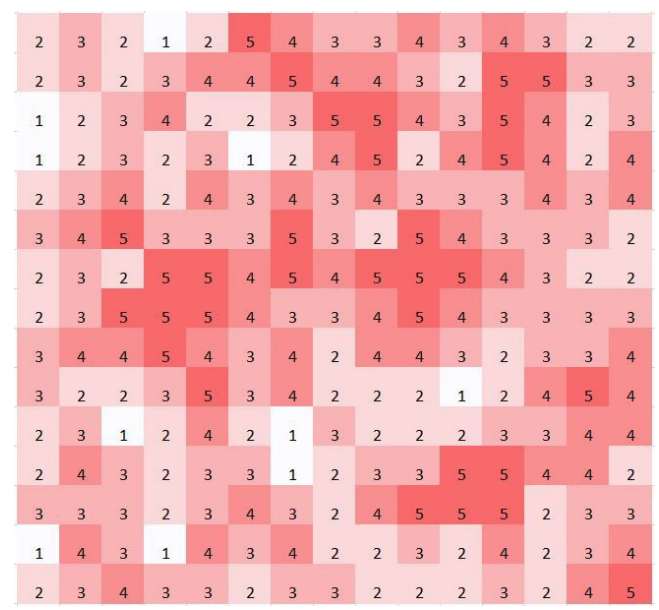

Fig. 5. HM made using "Conditional Formatting" in MS Excel 
cation can record cursor movement performed by visitors to websites, then analyze recordings including by generating a $\mathrm{HM}$ of places on the site that internet users 'visited' most often. Similar possibilities are offered by the Lucky Orange (Lucky Orange, n.d.) application, which also allows you to track user behavior on a selected website and visualize the results as a $\mathrm{HM}$. The Hotjar application also offers a similar tool (Hotjar, n.d.). According to the description by the application producer, its use helps in understanding user expectations of a website. Such visualizations based on mouse movements and eye-tracking are also used in empirical studies and usability studies (Špakov \& Miniotas, 2007; Vosskühler et al., 2008).

$\mathrm{HM}$ are also used to analyze damage to motor vehicles (Chen et al., 2018). One should also mention mobile applications, whose task is to detect access points of surrounding $\mathrm{Wi}-\mathrm{Fi}$ networks. Some of the applications allow Heat Maps of range and signal strength to be developed and overlaid on maps showing the location of buildings or maps showing the layout of rooms in a building.

\subsection{WebGIS tools}

One of the tools that enables users to interactively visualize data in the form of $\mathrm{HM}$ using an easy-to-use graphical interface is the Heatmapper network server (Babicki et al., 2016; Heatmapper, n.d.). The application is intended, first of all, to visualize biogeoinformatics data, and one of its modules has the ability to generate HM based on data containing geographical coordinates. The Geomap Heatmaps tool can display a Heat Map based on country, state, province or other such political boundaries, while the Geocoordinate tool "displays a Heat Map of densities based on a Gaussian Radius Multiplier, and values assigned to locations specified by latitude and longitude coordinates. $\mathrm{HM}$ visualization can also be developed using ArcGIS online, after importing the zipped point data in shapefile format, using the scale slider to set the 'Area of Influence' equivalent to radius and selecting a colour scale (How to Smart Map: Heat Maps. A Simple Guide to Using Density within ArcGIS Online., n.d.).

Tools and libraries for various programming languages to develop $\mathrm{HM}$ are also available for download on the web. One of them is Heat-
mapTool.com (HeatmapTool.Com, n.d.), which can be used to develop a Heat Map based on point data stored in a *.csv file and to visualize them using the Google Maps API. On the HeatMap Api website, you can access sample files and access an API that allows you to develop your own maps, which can be updated in real time (Google Maps Platform. Maps JavaScript API. Heatmap Layer, n.d.). A Heat Map can also be obtained using scripts available on the Internet for the Python programming language. Examples of such solutions include scripts available in Matplotlib libraries and heatmap.py (Golub, n.d.). The possibilities of implementing the $\mathrm{R}$ package to develop HM were presented by Barter and Yu (2018) highlighting that the $\mathrm{R}$ package is an extremely flexible and customizable platform for visualizing complex datasets.

The Open Layers library, which allows dynamic maps to be added to web pages, provides a tool to render vector data in the form of Heat Maps (Open Layers Documentation, n.d.). The user has the possibility to set the distance radius, among other things. Until December 2019, an experimental Fusion Table tool was available in the Google cloud (Google Fusion Tables, 2019). Based on tabular data containing point coordinates or a KML file, the tool enabled HM elaboration.

$\mathrm{HM}$ are used in visualizing, for example, the physical activity of a population. Strava and Endomondo, which are popular mobile apps for sportspeople (running, cycling), can record routes (Strava, n.d.). Based on Strava user activity from 2016 to 2017 , data was compiled and a worldwide map of these activities was developed. Now withdrawn from the Internet, the Endomondo app, which was competing with Strava, also used HM to develop and showcase app users' activity on Facebook.

Only a few of the tools and applications listed above give the ability to set parameters for generating and visualizing the spatial distribution of the phenomena studied. What is more, they are burdened with errors, especially in terms of the selection of colour scales and the degree of generalization. The Heatmapper application provides the most of the aforementioned features and options for developing $\mathrm{HM}$ (Heatmapper, n.d.). In addition, not all tools and applications allow maps to be developed according to the mapping principles adopted in cartography. Therefore, in the analysis, and as 
recommended by the Commission on Neocartography of the International Cartographic Association, the possibilities of developing Heat Maps in popular GIS programs were searched for, compiled and evaluated in terms of editing.

\subsection{Desktop GIS}

In order to select the software suitable for developing HM, we reviewed popular Desktop GIS software in terms of functionality and capabilities for map development in accordance with cartography rules. Due to popularity and extensive use, the following programs are included: ArcGIS, QGIS, Maplnfo and SAGA (tab. 1).

In ArcMap, the development of HM is possible with the help of tools located in the ArcToolBox tool box (ESRI, 2020). The Spatial Analyst Tools (Density) group provides Kernel Density tools to develop a HM based on point or surface data, while Line Density and Point Density can map the density of linear or point features. All of these tools allow the appropriate interpolation radius, output map parameters and color scale to be selected. The parameters of HM generation tools are described in the Help section, which greatly facilitates their proper matching. The ArcToolBox also includes a Hot Spot Analysis tool (Getis-Ord-Gi*) to visualize point or surface data hotspots. This tool identifies a statistically significant hotspot and cold spot using Getis-Ord-Gi* statistics. The Optimized Hot Spot Analysis tool placed in the same place, in turn, allows you to develop statistically significant hot and cold places in the form of square fields.

In application ArcGIS Pro the development of $\mathrm{HM}$ is possible with Heat Map option located in the Symbology (tool not available in ArcMap) and tools known also in Arc Map i.e. Hot Spot Analysis (Getis-Ord-Gi* ${ }^{*}$ and in Raster Functions(Kernel Density).

In the most popular geoinformatics software distributed under a free license, i.e. QGIS, it is possible to develop a thermal map using several tools. In the simplest way, a HM can be elaborated by using the Heat Map visualization option in the Layer Styling. It can create a map using a dozen available colour combinations or to develop a special colour scale for a map. The Cirkular date/Time Heatmap plug-in (QGIS Documentation 2.10, n.d.) available in QGIS 2.X was replaced in QGIS 3.X with the D3 Data
Visualization plug-in. In QGIS 3.X, in addition to those listed above, several options for developing HM are available in the Processing Toolbox sidebar. The Interpolation tool group has a Kernel Density Estimation (Heatmap) option that includes the selection of interpolation radius, raster map parameters, and colour scale. Also in the Sidebar Processing Toolbox, there are tools available in other GIS programs such as SAGA and GRASS (SAGA and GRASS modules in QGIS). The SAGA toolkit includes a Kernel density estimation tool that allows you to develop a map similar to the one elaborated with the abovementioned QGIS tool. Unfortunately, this module is not supported by a help option.

GRASS GIS v.kernel tool, also available in the side panel, generates a standard grid density map from vector point data using a floating kernel (Netek et al., 2018). For comparison purposes, the SAGA Kernel density estimation tool was tested with the Heatmap (Kernel Density Estimation) tool available in QGIS's Processing Toolbox sidebar, obtaining the same result maps (using this data and estimation parameters). In SAGA, which runs as a standalone computer program, HM can be elaborated using the Kernel Density tool (Geoprocessing, Grid, Gridding, Kernel Density Estimation) with the ability to set the radius and the parameters of the resulting map, and to develop a colour scale, though unfortunately to only a very limited extent.

In Maplnfo, the Create Raster module can be used to develop a $\mathrm{HM}$ along with the HotSpot Density point data interpolation method. You can select search modes, color scale editor and the radius and parameters of the resulting map.

\section{Assessment results and discussion}

As mentioned in chapter 2 the aim of the study was to identify and evaluate tools fully suitable for the development of HM maps. The task was to develop an HM using the same dataset with the different tools available in the GIS software.

The study was carried out by the authors of the article with the use of a research form. For its development the methods proposed in the geoportal evaluation studies (Dukaczewski, 2007; Siejka \& Ślusarski, 2014) verified in GIS application functional studies (Antoszkiewicz, 2018; Grzeszczyk, 2014) was used. 
Table 1. View of the comparable Heat Map development tools and their visualization (own elaboration)

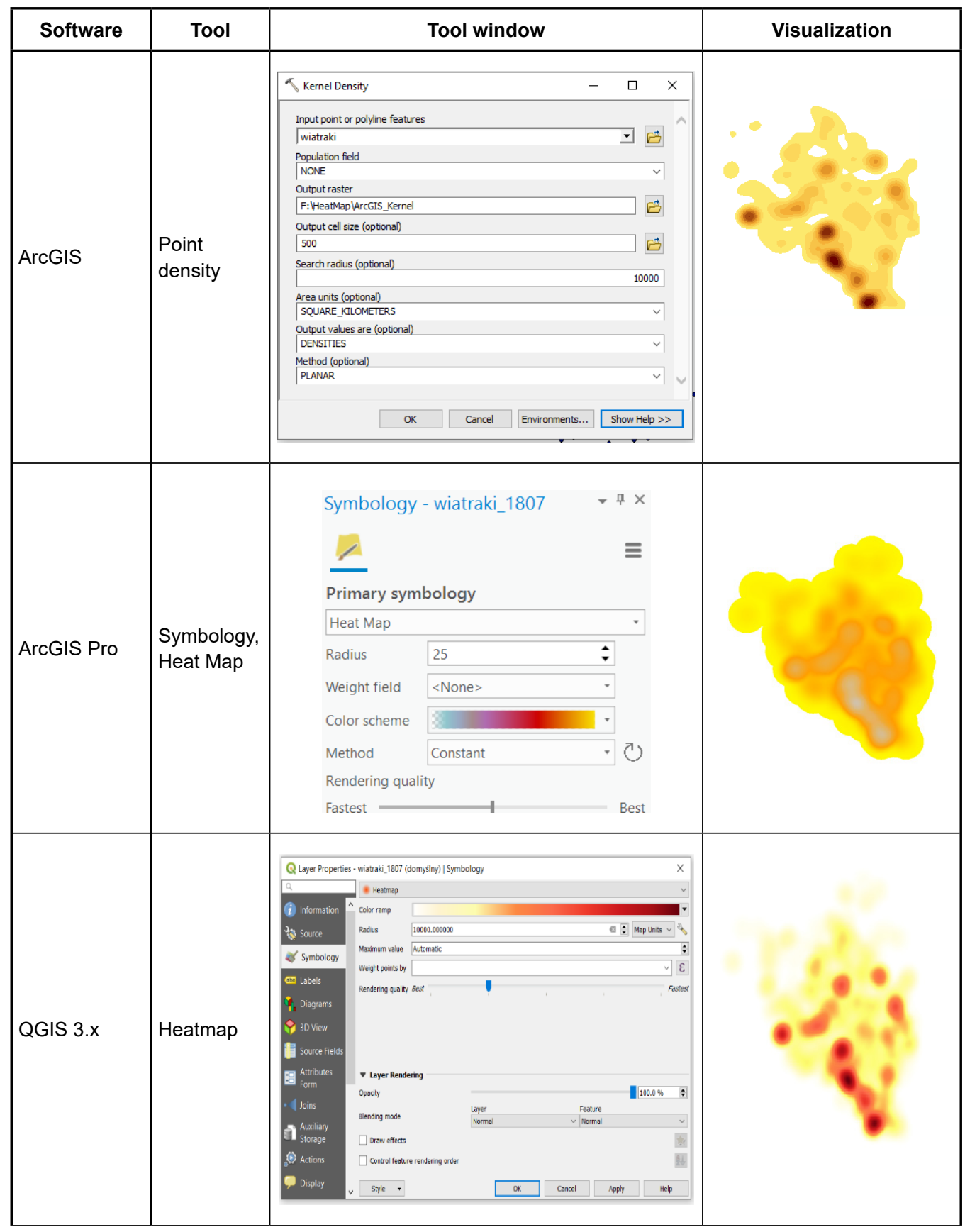




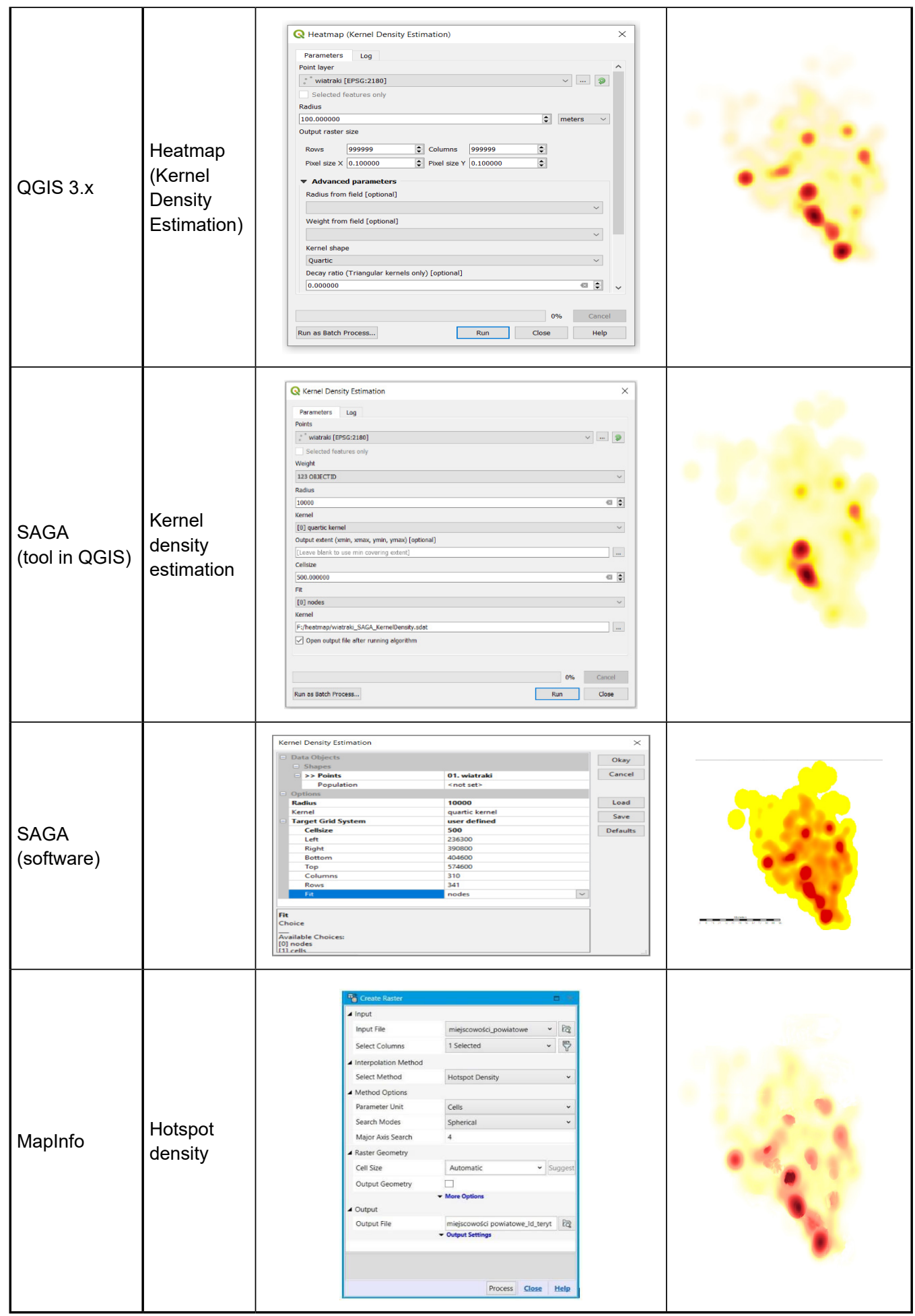


The research form contained seven questions to assess the application on a point scale of 0-2. A value of 0 indicates the absence of an element or its malfunction, 1 indicates an average performance, a value of 2 indicates correct operation with the possibility of modification.

In research were taken under consideration such features as: customizing HM parameters (radius, colour scheme) and type of map legend, but also technical support and difficulty of usage (Characteristics in table 2). The first two questions concerned the technical aspects of map preparation i.e. the capabilities of selecting the interpolation radius (1), and the possibilities of setting the parameters of the output map (2 and 3 ). The next question was related to the visualization efficiency, i.e. access to both finished and edited colour palettes (4). An important component of the evaluation of the application was access to assistance explaining the possibility of choosing parameters generated by $\mathrm{HM} \mathrm{(5)} \mathrm{and} \mathrm{the} \mathrm{ease} \mathrm{of} \mathrm{mapping} \mathrm{for}$ an experienced user of GIS software (6).

The last question concerns the ease of mapping by an experienced GIS user (7). The score assessment carried out during the development of the maps and the description of the computer programs made it possible to identify the software and tools with the widest possible set of options for professional mapping in accordance with the principles of cartography. he study includes also the presence of a module

Tab. 2. Tool evaluation questionnaire in popular GIS programs

\begin{tabular}{|c|c|c|c|c|c|c|c|c|}
\hline Characteristic & $\begin{array}{l}\text { ArcGIS 10.5/ } \\
\text { ArcGIS Pro }\end{array}$ & $\begin{array}{l}\text { ArcGIS 10.5/ } \\
\text { ArcGIS Pro }\end{array}$ & QGIS2.X & $\begin{array}{l}\text { QGIS2.X } \\
\text { QGIS 3.X }\end{array}$ & QGIS 3.X & $\begin{array}{l}\text { QGIS with } \\
\text { SAGA tools }\end{array}$ & $\begin{array}{l}\text { SAGA } \\
\text { (software) }\end{array}$ & Maplnfo \\
\hline Tool & $\begin{array}{l}\text { Hot Spot } \\
\text { Analysis } \\
(\text { Getis-Ord-Gi*), } \\
\text { Optimized Hot } \\
\text { Spot Analysis }\end{array}$ & $\begin{array}{l}\text { Kernel } \\
\text { Density, } \\
\text { Line Density, } \\
\text { Point Density }\end{array}$ & Heatmap & Heatmap & \begin{tabular}{|l|} 
Heatmap \\
(Kernel \\
Density \\
Estimation)
\end{tabular} & $\begin{array}{l}\text { Kernel } \\
\text { Density } \\
\text { Estimation }\end{array}$ & $\begin{array}{l}\text { Kernel } \\
\text { Density }\end{array}$ & $\begin{array}{l}\text { Hotspot } \\
\text { Density }\end{array}$ \\
\hline $\begin{array}{l}\text { Tool } \\
\text { location }\end{array}$ & $\begin{array}{l}\text { Toolbox, } \\
\text { Spatial } \\
\text { Statistics } \\
\text { Tools, } \\
\text { Mapping } \\
\text { Clusters }\end{array}$ & $\begin{array}{l}\text { Arc Toolbox, } \\
\text { Spatial } \\
\text { Analysis } \\
\text { Tools, } \\
\text { Density }\end{array}$ & $\begin{array}{l}\text { Raster, } \\
\text { Heatmap } \\
\text { (plugin) }\end{array}$ & $\begin{array}{l}\text { Symbology } \\
\text { (layer), } \\
\text { Heatmap }\end{array}$ & $\begin{array}{l}\text { Processing } \\
\text { Toolbox, } \\
\text { Interpolation }\end{array}$ & \begin{tabular}{|l} 
Processing \\
Toolbox, \\
Raster \\
creation \\
tools
\end{tabular} & $\begin{array}{l}\text { Geoprocessing, } \\
\text { Grid, Griding, } \\
\text { Kernel } \\
\text { Density } \\
\text { Estimation }\end{array}$ & $\begin{array}{l}\text { Create } \\
\text { Raster }\end{array}$ \\
\hline $\begin{array}{l}\text { Radius } \\
\text { (interpolation } \\
\text { parametres) }\end{array}$ & 2 & 2 & 2 & 2 & 2 & 2 & 2 & 2 \\
\hline $\begin{array}{l}\text { Output map } \\
\text { parameters }\end{array}$ & 2 & 1 & 1 & 0 & 1 & 1 & 2 & 2 \\
\hline Output file & 1 & 1 & 2 & 0 & 2 & 2 & 1 & 1 \\
\hline $\begin{array}{l}\text { Colour } \\
\text { scale editor }\end{array}$ & 2 & 2 & 1 & 2 & 2 & 2 & 1 & 1 \\
\hline Legend & 2 & 2 & 1 & 0 & 2 & 2 & 1 & 1 \\
\hline $\begin{array}{l}\text { Technical } \\
\text { support }\end{array}$ & 2 & 2 & 2 & 0 & 1 & 1 & 1 & 1 \\
\hline $\begin{array}{l}\text { Ease of map } \\
\text { elaboration }\end{array}$ & 0 & 2 & 2 & 2 & 2 & 2 & 0 & 2 \\
\hline Sum & 11 & 12 & 11 & 6 & 12 & 11 & 8 & 10 \\
\hline
\end{tabular}


(option) that allows the generation of the map, its place of occurrence in the structure of the program (tab. 2).

Among the desktop software, the most refined $\mathrm{HM}$ development tools seem to be the tools provided in ArcGIS, QGIS, which contain the full range of options available and, more importantly, satisfactory documentation to facilitate their selection. However, it is worth noting that both ArcGIS and QGIS (with SAGA tools) have several options for elaboration of $\mathrm{HM}$, in the fields of both visualization and parameter settings of the developed maps, which enable them to be developed following cartographic rules.

The research on the evaluation of HM development tools in popular GIS software shows that the Kernel Density tools available in ArcGIS and QGIS are the most developed. Highquality maps can also be generated using the Hot Spot Analysis (Getis-Ord-Gi *) tool from ArcGIS and the Heatmap plug-in available from QGIS 2.X versions. Mapinfo has only one tool (Hotspot Density) for developing HM, due to poor technical support, this tool was rated a bit lower (11 points). The disadvantage of SAGA (software), in the aspect of HM is the difficult interface of software, poor possibilities of editing the colour palette and a weak module for developing final maps, in the study the program was rated at 8 points. One of the drawbacks of drawing $H M$ in QGIS is its overly simplified option of making maps using Layer Styling and the unstable functioning of the Kernel Density tool in subsequent versions of the software.

To sum up, most of the analyzed tools are suitable for the development of HM in accordance with the principles of cartography. However, due to the level of sophistication in GIS, HM tools are difficult to access for people outside the GIS environment.

\section{Summary}

HM are a very popular type of data visualization, which is used primarily in digital and especially web cartography. Based on the previous literature, as well as map analysis, the definition of $\mathrm{HM}$ in a cartographic context can be proposed. The cartographic Heat Map is a graphical representation of geographic data density in the form of a raster map elaborated by applying kernel density estimation on point or linear input data. In such understanding, the value of each pixel in the output map is calculated by the number of overlapping areas within the given radius generated around the input data. HM are commonly used when: 1) the graphical capacity of the single symbol map is too small and thus the map is barely readable; 2 ) one is focusing on depicting the geographical distribution of data, and choropleth maps or graduated symbols maps are limited by statistical boundaries and do not reflect data spatial distribution; 3 ) the aim is to prepare such a map fast (which is less time-consuming than a dot map), especially for the Internet and interactive media.

Commonly available data obtained by various types of measurements stored in databases are more and more often used for visualization - both in the form of individual maps as well as elements of infographics. Due to the easy method of development and the availability of online and free GIS tools enabling the development of $\mathrm{HM}$, one should expect the increasing popularity of this method. For example the development of mobile GIS software, including data collectors, influenced the high availability of newly recorded data. We should expect frequent use of these tools for simple visualization of the data collected in this way. For instance, data collection in Collector for ArcGIS can be mapped in ArcGIS online, also as HM visualization. It is becoming more and more common to use $\mathrm{HM}$ to visualize registered traces or points in sports activity - both recreational and competitive (Bornn et al., 2018; Goldsberry, 2012; McHale \& Relton, 2018; Perin et al., 2013), analyzes of criminal incidents and offenses (Anderson, 2009; Chainey et al., 2008; Plug et al., 2011), analyzes using eye-tracking measurements as well as analyzes of various types of imaging in medicine. These are very often visualizations developed outside the GIS environment or by people who do not have the knowledge and skills of map editing. Therefore, for these users, there are simple tools available online to visualize phenomena and spatially interpret them. Among the proposed solutions from the webGIS software, the Heatmapper (Heatmapper, n.d.) application deserves attention. It enables the visualization of spatial data with the use of several cartographic methods and includes a developed set of features for their elaboration.

Concerning the article's main issue, it should be clearly noted that the use of HM, in both 
digital and analogue cartography, has many possibilities but also limitations. Certainly, HM are maps 'for quick reading,' and (with the right tools) also 'for quick design and elaboration.' In an illustrative and legible way, it allows spatial visualization of the density of phenomena. However, the increasing popularity of this map type and its widespread use can lead to subjective choices about the variables used to make it. The key parameter is the radius of the kernel estimation, which properly selected, can emphasize the density or, conversely, 'flatten' the image of the phenomenon. Other methodological variables may also favor falsification (intentional or not) of the phenomenon presented. The development of maps is, in principle, linked to reality modeling, which requires simplification and deliberate choices that may or may not lead to falsification (intentional or not) (Mon-

\section{Literature}

Anderson, T. K. (2009). Kernel density estimation and K-means clustering to profile road accident hotspots. Accident Analysis \& Prevention, 41(3), 359-364. https://doi.org/10.1016/j.aap.2008.12.014

Antoszkiewicz, M. (2018). Analiza porównawcza wybranych polskojęzycznych serwisów mapowych. University of Warsaw.

Babicki, S., Arndt, D., Marcu, A., Liang, Y., Grant, J. R., Maciejewski, A., \& Wishart, D. S. (2016). Heatmapper: Web-enabled heat mapping for all. Nucleic Acids Research, 44(W1), W147-W153. https:// doi.org/10.1093/nar/gkw419

Barter, R. L., \& Yu, B. (2018). Superheat: An R Package for Creating Beautiful and Extendable Heatmaps for Visualizing Complex Data. Journal of Computational and Graphical Statistics, 27(4), 910-922. https://doi.org/10.1080/10618600.2018.1473780

Board, C. (1978). Map Reading Tasks Appropriate In Experimental Studies In Cartographic Communication. Cartographica: The International Journal for Geographic Information and Geovisualization, 15(1), 1-12. https://doi.org/10.3138/AG15-V2523726-W346

Bornn, L., Cervone, D., \& Fernandez, J. (2018). Soccer analytics: Unravelling the complexity of "the beautiful game". Significance, 15(3), 26-29. https://doi. org/10.1111/j.1740-9713.2018.01146.x

Borzuchowska, J. (2007). Poszukiwanie nowych metod kartograficznych dla mapowania problemów społecznych. In W. Żyszkowska \& W. Spallek (Eds.), Główne problemy współczesnej kartografii. Kartograficzne programy komputerowe. Konfrontacja teorii z praktyka (pp. 135-144). Uniwersytet Wrocławski. monier, 2018). According to the authors, HM, because of the multitude of methodological variables affecting its form, is particularly susceptible to deficient map elaboration and, consequently, misinterpretation of phenomena by users. This topic, particularly in regards to the correct interpretation of HM, should be developed in subsequent studies.

Funding. This research was funded by the National Science Centre, Poland, grant number UMO-2016/23/B/HS6/03846, "Evaluation of cartographic presentation methods in the context of map perception and effectiveness of visual transmission".

Acknowledgments. We express our thanks to EMPREK Team colleagues Izabela Gołębiowska, Jolanta Korycka-Skorupa, Izabela Karsznia, and Tomasz Nowacki.

Chainey, S., Tompson, L., \& Uhlig, S. (2008). The Utility of Hotspot Mapping for Predicting Spatial Patterns of Crime. Security Journal, 21(1-2), 4-28. https://doi.org/10.1057/palgrave.sj.8350066

Chen, K., Haller, J. L., Kanade, T., \& Georghiades, A. S. (2018). Heat map of vehicle damage. https://patents.google.com/patent/US9886771B1/en

DeBoer, M. (2015). Understanding the Heat Map. Cartographic Perspectives, 80, 39-43. https://doi. org/10.14714/CP80.1314

Dempsey, C. (2012). Heat Maps in GIS. https://www. gislounge.com/heat-maps-in-gis/

Dukaczewski, D. (2007). Wojewódzkie portale informacji przestrzennej. Roczniki Geomatyki, V(3), 37-56.

ESRI. (2020). Can a heat map be created in ArcMap? https://support.esri.com/en/technical-article/0000 12211

Faby, H., \& Koch, A. (2010). From maps to neo-cartography. In T. Bandrova \& M. Konecny (Eds.), Proceedings of the 3rd Interational Conference on Cartography \& GIS (p. 6).

Goldsberry, K. (2012). CourtVision: New Visual and Spatial Analytics for the NBA. MIT Sloan Sports Analytics Conference. https://www.semanticscholar. org/paper/CourtVision-\%3A-New-Visual-and-SpatialAnalytics-for-Goldsberry/46e4a7271de62e911 8625dec935c4aef1bc0ea74

Gołebiowska, I., \& Coltekin, A. (2020). Rainbow Dash: Intuitiveness, interpretability and memorability of the rainbow colour scheme in visualization. IEEE Transactions on Visualization and Computer Graphics, 1. https://doi.org/10.1109/TVCG.2020.3035823

Golub, S. (n.d.). Heatmap.py. Retrieved 24 April 2021, from http://www.sethoscope.net/heatmap/ 
Google Fusion Tables. (2019). https://en.wikipedia. org/wiki/Google_Fusion_Tables

Google Maps Platform. Maps JavaScript API. Heatmap Layer. (n.d.). Retrieved 26 April 2021, from https:// developers.google.com/maps/documentation/ javascript/heatmaplayer

Gotlib, D. (2008). Nowe oblicza kartografii - Internet a kartografia. Polski Przegląd Kartograficzny, 40(3), 237-246.

Gove, R., Gramsky, N., Kirby, R., Sefer, E., Sopan, A., Dunne, C., Shneiderman, B., \& Taieb-Maimon, M. (n.d.). NetVisia: Heat Map \& Matrix Visualization of Dynamic Social Network Statistics \& Content. 19-26. https://doi.org/10.1109/PASSAT/SocialCom. 2011.216

Grzeszczyk, M. (2014). Porównanie funkcjonalności internetowych aplikacji mapowych do prezentacji metod oznaczania obiektów punktowych i liniowych [Bachelor thesis]. University of Warsaw.

Guo, H., Zhang, W., Ni, C., Cai, Z., Chen, S., \& Huang, X. (2020). Heat map visualization for electrocardiogram data analysis. BMC Cardiovascular Disorders, 20(1). https://doi.org/10.1186/s12872020-01560-8

Heatmapper. (n.d.). Retrieved 24 April 2021, from http://www.heatmapper.ca/

HeatmapTool.com. (n.d.). Retrieved 24 April 2021, from HeatmapTool.com

Hotjar. (n.d.). Retrieved 24 April 2021, from https:// www.hotjar.com/

How to Smart Map: Heat Maps. A simple guide to using density within ArcGIS Online. (n.d.). Retrieved 26 April 2021, from https://www.arcgis.com/apps/ Cascade/index.html?appid=ca7e12f6e8c0474bb 4269889bda8ce41

Kukułka, M., \& Gotlib, D. (2014). Wpływ zjawiska neokartografii na rozwój serwisów internetowych udostępniających informacje przestrzenne. Polski Przegląd Kartograficzny, 46(1), 34-46.

Lucky Orange. (n.d.). Retrieved 24 April 2021, from https://www.luckyorange.com/heat-maps.php

McHale, I. G., \& Relton, S. D. (2018). Identifying key players in soccer teams using network analysis and pass difficulty. European Journal of Operational Research, 268(1), 339-347. https://doi.org/10.1016/ j.ejor.2018.01.018

Microsoft Excel Heatmap. (n.d.). Retrieved 24 April 2021, from https://www.excel-easy.com/examples/ heat-map.html

Monmonier, M. S. (2018). How to lie with maps. (Third edition). The University of Chicago Press.

Moon, J.-Y., Jung, H.-J., Moon, M. H., Chung, B. C., \& Choi, M. H. (2009). Heat-map visualization of gas chromatography-mass spectrometry based quantitative signatures on steroid metabolism. Journal of the American Society for Mass Spectrometry, 20(9), 1626-1637. https://doi.org/10.1016/ j.jasms.2009.04.020
Nelson, J. K., \& MacEachren, A. M. (n.d.). User-centered Design and Evaluation of a Geovisualization Application Leveraging Aggregated Quantified-Self Data. Cartographic Perspectives, 96, 7-31. https:// doi.org/10.14714/CP96.1631

Netek, R., Pour, T., \& Slezakova, R. (2018). Implementation of Heat Maps in Geographical Information System - Exploratory Study on Traffic Accident Data. Open Geosciences, 10(1), 367-384. https:// doi.org/10.1515/geo-2018-0029

Netek, R., Tomecka, O., \& Brus, J. (2019). Performance Testing on Marker Clustering and Heatmap Visualization Techniques: A Comparative Study on JavaScript Mapping Libraries. ISPRS International Journal of Geo-Information, 8(8), 348. https:// doi.org/10.3390/ijgi8080348

Opach, T., \& Nossum, A. (2011). Evaluating the Usability of Cartographic Animations With Eye-Movement Analysis. Proceedings of the 25th International Cartography Conference ICC, 11. https:// icaci.org/files/documents/ICC_proceedings/ICC2011/ Oral\%20Presentations\%20PDF/A3-Visualisation $\% 20$ efficiency/CO-005.pdf

Open Layers Documentation. (n.d.). Retrieved 26 April 2021, from https://openlayers.org/en/latest/ apidoc/module-ol_layer_Heatmap-Heatmap.html

Pánek, J., \& Benediktsson, K. (2017). Emotional mapping and its participatory potential: Opinions about cycling conditions in Reykjavík, Iceland. Cities, 61, 65-73. https://doi.org/10.1016/j.cities. 2016.11.005

Perin, C., Vuillemot, R., \& Fekete, J.-D. (2013). SoccerStories: A Kick-off for Visual Soccer Analysis. IEEE Transactions on Visualization and Computer Graphics, 19(12), 2506-2515. https://doi.org/10.1109/ TVCG.2013.192

Pettit, C., Widjaja, I., Russo, P., Sinnott, R., Stimson, R., \& Tomko, M. (2012). Visualisation support for exploring urban space and place. ISPRS Annals of Photogrammetry, Remote Sensing and Spatial Information Sciences, I-2, 153-158. https://doi. org/10.5194/ISPRSANNALS-I-2-153-2012

Pleil, J. D., Stiegel, M. A., Madden, M. C., \& Sobus, J. R. (2011). Heat map visualization of complex environmental and biomarker measurements. Chemosphere, 84(5), 716-723. https://doi.org/10.1016/j. chemosphere.2011.03.017

Plug, C., Xia, J., \& Caulfield, C. (2011). Spatial and temporal visualisation techniques for crash analysis. Accident Analysis \& Prevention, 43(6), 1937-1946. https://doi.org/10.1016/j.aap.2011.05.007

Polczynski, M., \& Polczynski, M. (2014). A Microsoft VBA Application for Generating Heat Maps. Transactions in GIS, 18(5), 783-791. https://doi.org/ $10.1111 /$ tgis. 12082

QGIS Documentation 2.10. (n.d.). Retrieved 24 April 2021, from https://docs.qgis.org/3.10/en/docs/index. $\mathrm{html}$ 
Rosenbaum, L., Hinselmann, G., Jahn, A., \& Zell, A. (2011). Interpreting linear support vector machine models with heat map molecule colouring. Journal of Cheminformatics, 3(1). https://doi.org/10.1186/ 1758-2946-3-11

Sainio, J., Westerholm, J., \& Oksanen, J. (2015). Generating Heat Maps of Popular Routes Online from Massive Mobile Sports Tracking Application Data in Milliseconds While Respecting Privacy. ISPRS International Journal of Geo-Information, 4(4), 1813-1826. https://doi.org/10.3390/ijgi4041813

Scott, N., Green, C., \& Fairley, S. (2016). Investigation of the use of eye tracking to examine tourism advertising effectiveness. Current Issues in Tourism, 19(7), 634-642. https://doi.org/10.1080/13 683500.2014 .1003797

Siejka, M., \& Ślusarski, M. (2014). Ocena geoportali internetowych powiatów, na wybranych przykładach oraz według ustalonych kryteriów. Infrastruktura i Ekologia Terenów Wiejskich, 2(2), 545-555.

Silva, A. T., Ribone, P. A., Chan, R. L., Ligterink, W., \& Hilhorst, H. W. M. (2016). A Predictive Coexpression Network Identifies Novel Genes Controlling the Seed-to-Seedling Phase Transition in Arabidopsis thaliana. Plant Physiology, 170(4), 2218-2231. https://doi.org/10.1104/pp.15.01704
Silverman, B. W. (1986). Density Estimation for Statistics and Data Analysis. Chapman and Hall.

Smartlook. (n.d.). Retrieved 24 April 2021, from https:// www.smartlook.com/

Špakov, O., \& Miniotas, D. (2007). Visualization of Eye Gaze Data using Heat Maps. Elektronika Ir Elektrotechnika, 74(2), 55-58.

Strava. (n.d.). https://www.strava.com/heatmap\#5.30/ 8.83889/51.91208/hot/all

Vosskühler, A., Nordmeier, V., Kuchinke, L., \& Jacobs, A. M. (2008). OGAMA (Open Gaze and Mouse Analyzer): Open-source software designed to analyze eye and mouse movements in slideshow study designs. Behavior Research Methods, 40(4), 1150-1162. https://doi.org/10.3758/BRM.40.4.1150

Wilkinson, L., \& Friendly, M. (2009). The History of the Cluster Heat Map. The American Statistician, 63(2), 179-184. https://doi.org/10.1198/tas.2009.0033

Yeap, E., \& Uy, I. (2014). Marker Clustering and Heatmaps: New features in the Google Maps Android API Utility Library. https://mapsplatform.googleblog.com/ 2014/02/marker-clustering-and-heatmaps-new.html

Zhan, Z., Zhang, L., Mei, H., \& Fong, P. (2016). Online Learners' Reading Ability Detection Based on Eye-Tracking Sensors. Sensors, 16(9), 1457. https:// doi.org/10.3390/s16091457 